\title{
Clinical significance of anti-mitochondrial antibodies in a patient with chronic graft-versus-host disease following hematopoietic stem cell transplantation
}

\author{
Dong Hyun Lee ${ }^{1}$, Seok Jae Huh ${ }^{1}$, Hyun Hwa Yoon ${ }^{1}$, Sung Woo Lee ${ }^{1}$, Kyeong Hee Kim ${ }^{2}$, Sung-Hyun Kim ${ }^{1}$ \\ Departments of ${ }^{1}$ Internal Medicine and ${ }^{2}$ Laboratory Medicine, Dong-A University College of Medicine, Busan, Korea
}

p-ISSN 1738-7949 / e-ISSN 2092-9129 http://dx.doi.org/10.5045/kjh.2011.46.3.200 Korean J Hematol 2011;46:200-2.

Received on May 23, 2011

Revised on July 12, 2011

Accepted on August 5, 2011

\author{
Correspondence to \\ Sung-Hyun Kim, M.D., Ph.D. \\ Department of Internal Medicine, Dong-A \\ University College of Medicine, 3-1, \\ Dongdaeshin-dong, Seo-gu, Busan \\ 602-715, Korea \\ Tel: +82-51-240-2608 \\ Fax: $+82-51-246-5044$ \\ E-mail: kshmoon@dau.ac.kr \\ (C) 2011 Korean Society of Hematology
}

Recent studies indicate that patients with chronic graft-versus-host disease (GVHD) are not expected to show positivity for anti-mitochondrial antibody (AMA), which is a specific disease marker for primary biliary cirrhosis (PBC). A differential diagnosis between PBC and hepatic involvement of GVHD based on clinical manifestations and pathologic study is difficult because both diseases show similar results. Therefore, the presence of AMA may be important for distinguishing each disease. Here, we report a case of hepatic involvement of chronic GVHD with positive AMA, in which the pathologic findings and initial presentation of clinical findings were compatible with both PBC and chronic GVHD.

Key Words Autoantibody, Anti-mitochondrial antibody, Chronic graft-versus-host disease, Hematopoietic stem cell transplantation

\section{INTRODUCTION}

Primary biliary cirrhosis (PBC) and hepatic involvement in chronic graft-versus-host disease (GVHD) following hematopoietic stem cell transplantation (HSCT) have many similarities. Both show similar clinical manifestations, and laboratory and pathologic findings. Furthermore, in previous studies, anti-mitochondrial antibodies (AMAs) were detected in patients with chronic GVHD even though AMA is a very specific disease marker for PBC [1-4]. Recently, however, several studies have shown negative AMA in the serum of chronic GVHD patients following HSCT, and it has been thought that the previously reported results may have been false positives, with AMA being a disease marker for PBC only [5]. Here, we present a case of AMA-positive hepatic involvement in chronic GVHD following HSCT, showing pathologic compatibility with $\mathrm{PBC}$.

\section{CASE REPORT}

A 28-year-old woman presented with fever and generalized myalgia in July 2008. She was diagnosed as having acute myeloid leukemia (AML) with $t(6 ; 9)$. She was treated with induction chemotherapy followed by HLA fully matched peripheral blood stem cell transplantation from her brother in December 2008.

Her liver function test was normal before treatment for AML, and there were no symptoms suggesting liver disease or autoimmune disorder. She did not have a history of liver disease, skin disorder, or autoimmune disorder. The viral marker tests against hepatitis were negative.

Six months after transplantation, in June 2009, she developed a skin rash on her extremities, together with anorexia and nausea. Skin biopsy was performed on suspicion of skin involvement in chronic GVHD. Her skin showed lymphocyte-dominated superficial perivascular dermatitis with exocytosis of the epidermis, and she was diagnosed as having skin involvement in chronic GVHD. Of her laboratory findings, hemoglobin was $9.8 \mathrm{~g} / \mathrm{dL}$, white blood cell count

\footnotetext{
This is an Open Access article distributed under the terms of the Creative Commons Attribution Non-Commercial License (http://creativecommons.org/licenses/by-nc/3.0)
} which permits unrestricted non-commercial use, distribution, and reproduction in any medium, provided the original work is properly cited. 
was $5.2 \times 10^{9} / \mathrm{L}$ (neutrophils $38.4 \%$, lymphocytes $41.2 \%$, monocytes $12.2 \%$, eosinophils $7.8 \%$ ), aspartate aminotransferase (AST) was $35 \mathrm{IU} / \mathrm{L}$, alanine aminotransferase (ALT) was $91 \mathrm{IU} / \mathrm{L}$, alkaline phosphatase (ALP) was $540 \mathrm{IU} / \mathrm{L}$, and total bilirubin was $0.4 \mathrm{mg} / \mathrm{dL}$, with direct bilirubin $0.2 \mathrm{mg} / \mathrm{dL}$. There was no definite cause to explain the abnormal result of the liver function test except hepatic involvement in chronic GVHD. She had been treated with cyclosporine, and the prescription was changed to prednisolone (PRS) $15 \mathrm{mg} /$ day, FK506 $2 \mathrm{mg} /$ day, and ursodeoxycholic acid (UDCA), $600 \mathrm{mg} /$ day. Immunosuppressive agents were tapered slowly owing to chronic GVHD. She continued taking immunosuppressive agents until March 18, 2010.

On July 1, 2010, 4 months after cessation of immunosuppressive agents, she presented with fatigue, generalized pruritus, and arthralgia on knees, elbows, and wrists. On physical examination, both her knees were swollen with no heat or redness, and the skin on her extremities was covered with multiple scratches. Blood investigation showed hemoglobin of $13.5 \mathrm{~g} / \mathrm{dL}$, white blood cell count of $16.0 \times 10^{9} / \mathrm{L}$ [neutrophils $36 \%$, lymphocytes $23.3 \%$, monocytes $10.8 \%$, eosinophils $\left.29.3 \%\left(6.08 \times 10^{9} / \mathrm{L}\right)\right]$, AST of $50 \mathrm{IU} / \mathrm{L}$, ALT of $47 \mathrm{IU} / \mathrm{L}, \mathrm{ALP}$ of $472 \mathrm{IU} / \mathrm{L}$, and total bilirubin of $0.5 \mathrm{mg} / \mathrm{dL}$ with direct bilirubin of $0.2 \mathrm{mg} / \mathrm{dL}$.

Autoantibodies were tested to investigate autoimmune disease, and the results showed positivity for antinuclear antibody (ANA) and AMA subtype M2. Indirect immunofluorescence (IIF) using both rat tissue and Hep2 cells, and an immunoblot assay (IBL) were used for detecting AMA, and the results were consistent on repeated testing. Other autoantibodies against nRNP/Sm, Sm, SS-A, Ro-52, SSB, Scl-70, PM-Scl, Jo-1, CENP-B, PCNA, dsDNA, nucleosome, histone, and ribosomal $\mathrm{P}$ protein were negative.

Ultrasonography of her abdomen was normal, and a liver biopsy was performed. The liver specimen showed chronic hepatitis accompanied by mild lobular activity with lipogranuloma, cholestasis, pseudo-rosette formation, and ballooning degeneration. Mild porto-periportal activity with biliary epithelial damage was also observed, and bile ductule proliferation with occasional plasma cell infiltration was seen (Fig. 1). Portal fibrosis was present and all the findings were consistent with PBC. However, clinically she was considered to have hepatic involvement, joint manifestation, and skin involvement in chronic GVHD. It was decided that she should be treated with immune suppression therapy and a high dose of UDCA. PRS $20 \mathrm{mg} /$ day, FK506 $1 \mathrm{mg} /$ day, and UDCA $900 \mathrm{mg} /$ day were prescribed. Celecoxib 400 $\mathrm{mg}$ /day was also used to manage arthralgia.

On August 5, 2010, her blood count showed hemoglobin of $13.9 \mathrm{~g} / \mathrm{dL}$, white blood cell count of $14.8 \times 10^{9} / \mathrm{L}$ (neutrophils $47.4 \%$, lymphocytes $40.1 \%$, monocytes $11.3 \%$, eosinophils $0.8 \%$ ), AST of $17 \mathrm{IU} / \mathrm{L}$, ALT of $19 \mathrm{IU} / \mathrm{L}$, ALP of $279 \mathrm{IU} / \mathrm{L}$, and total bilirubin of $0.5 \mathrm{mg} / \mathrm{L}$. Her arthralgia, eosinophilia, and hepatic dysfunction improved.

On February 10, 2011, FK506 was suspended, but she complained of aggravated arthralgia after 6 weeks. FK506 was readministered at $1 \mathrm{mg} /$ day, which was the previous

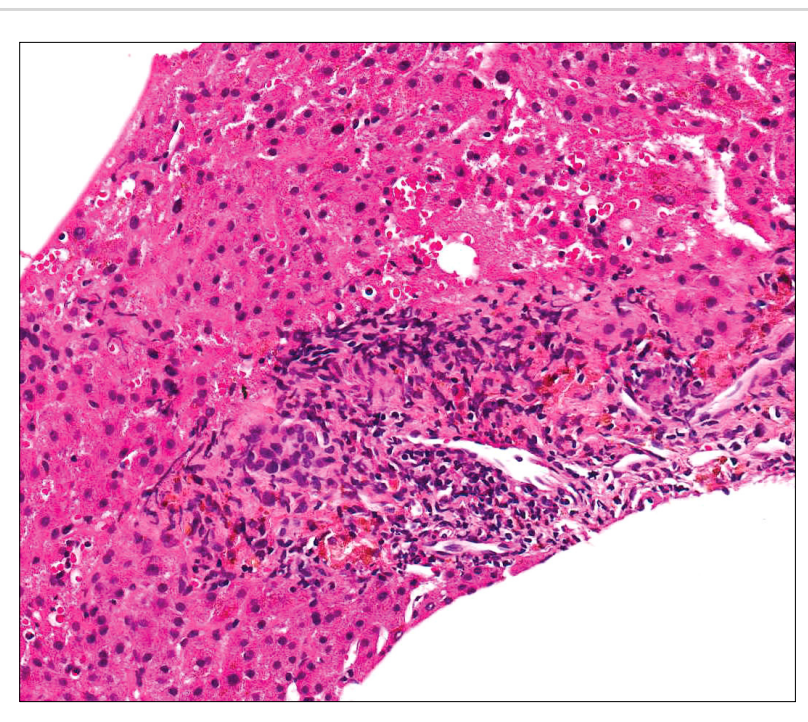

Fig. 1. Liver biopsy reveals mild biliary epithelial damage of portal tract, lymphocytic infiltraion and mild peacemeal necrosis.

maintenance dose, and her arthralgia soon improved.

On March 31, 2011, AMA was again checked using IIF and IBL and was again positive, but her symptoms improved and blood investigations did not show eosinophilia or abnormal liver function, with hemoglobin of $14.5 \mathrm{~g} / \mathrm{dL}$, white blood cell count $13.1 \times 10^{9} / \mathrm{L}$ (neutrophils $41.7 \%$, lymphocytes $40.7 \%$, monocytes $13.2 \%$, eosinophils $3.6 \%$ ), AST of $28 \mathrm{IU} / \mathrm{L}$, ALT of 19 IU/L, ALP of 289 IU/L, total bilirubin of 0.5 $\mathrm{mg} / \mathrm{dL}$, and direct bilirubin of $0.3 \mathrm{mg} / \mathrm{dL}$.

To date, she has been taking PRS $5 \mathrm{mg}$, FK506 $1 \mathrm{mg}$, and UDCA $900 \mathrm{mg}$.

\section{DISCUSSION}

Although the mechanism of chronic GVHD is obscure, there are similarities between chronic GVHD and autoimmune disease. In the present case, the patient complained of fatigue, pruritus, and arthralgia, which are present in PBC. Although more than half of PBC patients are asymptomatic, fatigue is present in $80 \%$ and pruritus is present in $20-70 \%$ of symptomatic patients [6]. In addition, inflammatory arthropathy is present in $4-50 \%$ of PBC patients [7]. Because differential diagnosis of both diseases from clinical symptoms and pathologic findings is difficult, AMA is an important laboratory finding to support PBC diagnosis.

Autoantibodies are frequently detected in the serum of chronic GVHD patients with or without autoimmune manifestations. Together with other autoantibodies, such as ANA, AMA has also been detected in the serum of chronic GVHD patients, and a positivity rate of $4-81 \%$ has been reported [1-4].

However, more recently, results showing negativity in the AMA test have been reported, and positive reports are 
thought to have been false positives [8, 9]. Quaranta et al. checked AMA in the serum of 89 chronic GVHD patients by IIF, IBL, and enzyme-linked immunosorbent assay (ELISA) but no patient was positive for AMA [8]. They explained the cause of the negative AMA result, which was different from previous reports, as follows. First, combination treatment with corticosteroids, cyclosporine, thalidomide, and FK506 had been used recently, although there was no data reporting any correlation between antibody production and such medications. Second, mismatched proteins against mitochondrial antigens were demonstrated in PBC patients in the study by Siegert et al. [2], which showed the highest frequency of AMA. Siegert et al. reported the molecular masses of matched proteins to be $63 / 60$ and $22 \mathrm{kDa}$, whereas Quaranta et al. [8] reported molecular masses of 74, 56, and $52 \mathrm{kDa}$.

Approximately $10-15 \%$ of $\mathrm{PBC}$ patients are negative for AMA, and laboratory tests have placed emphasis on detecting AMA in AMA-negative PBC patients. Many centers use IIF for detecting AMA; however, newly developed methods, including those using ELISA, have been used. The sensitivity of ELISA is superior to that of IIF, although, with regard to its specificity, IIF is not inferior to ELISA [10, 11].

In our case, the patient was tested for AMA using IIF and IBL. The results showed positivity on repeated tests and tests over time. The presence of AMA in her serum was therefore considered to be confirmed. Autoantibody tests, including AMA, were not performed at initial diagnosis of leukemia. Autoantibody testing is not routine in leukemia, and she did not have any symptoms to cause us to suspect autoimmune disorder. Furthermore, her liver function tests were within normal limits and she did not have any symptoms of arthropathy or dermopathy before transplantation. Because this patient was not part of a prospective study, there was no reason to evaluate the presence of autoantibodies.

The treatments for chronic GVHD and PBC are different. Most chronic GVHDs are treated with immunosuppressive agents such as glucocorticoids, FK506, and cyclosporine, whereas PBCs are commonly treated with UDCA. However, corticosteroids, colchicine, and immunosuppressive agents such as cyclosporine, can also be used for PBCs, since they are thought to be adjuvants [12]. Our patient's symptoms responded to immune suppression therapy, but the treatment also included a high dose of UDCA. It is difficult to judge whether PBC responded to UDCA or chronic GVHD responded to immune suppression therapy. However, on balance, we considered that she had hepatic involvement of chronic GVHD, because she was young and had developed these problems following HSCT.

Many autoantibodies have been reported in patients with chronic GVHD. Detecting the presence of AMA is more important than for other autoantibodies, because $\mathrm{PBC}$ shows very similar symptoms to hepatic involvement of chronic GVHD, making differential diagnosis an important aspect when choosing treatment modality. In this case, it was difficult to decide whether to continue the high dose of UDCA treatment. Therefore, confirming the possibility of the presence of AMA in the serum of chronic GVHD patients was important. Recent reports seem to consider that AMA would not be detected in the serum of chronic GVHD patients $[1,8]$. However, further studies focusing on AMA using various detection modalities are required, because previous studies in which AMA has been detected in GVHD patients certainly exist. This case is significant in this regard.

\section{REFERENCES}

1. Kier P, Penner E, Bakos S, et al. Autoantibodies in chronic GVHD: high prevalence of antinucleolar antibodies. Bone Marrow Transplant 1990;6:93-6.

2. Siegert W, Stemerowicz R, Hopf U. Antimitochondrial antibodies in patients with chronic graft-versus-host disease. Bone Marrow Transplant 1992;10:221-7.

3. Patriarca F, Skert C, Sperotto A, et al. The development of autoantibodies after allogeneic stem cell transplantation is related with chronic graft-vs-host disease and immune recovery. Exp Hematol 2006;34:389-96.

4. Rouquette-Gally AM, Boyeldieu D, Gluckman E, Abuaf N, Combrisson A. Autoimmunity in 28 patients after allogeneic bone marrow transplantation: comparison with Sjögren syndrome and scleroderma. Br J Haematol 1987;66:45-7.

5. Tyndall A, Dazzi F. Chronic GVHD as an autoimmune disease. Best Pract Res Clin Haematol 2008;21:281-9.

6. Lindor KD, Gershwin ME, Poupon R, Kaplan M, Bergasa NV, Heathcote EJ. Primary biliary cirrhosis. Hepatology 2009;50: 291-308.

7. Chi ZC, Ma SZ. Rheumatologic manifestations of hepatic diseases. Hepatobiliary Pancreat Dis Int 2003;2:32-7.

8. Quaranta S, Shulman H, Ahmed A, et al. Autoantibodies in human chronic graft-versus-host disease after hematopoietic cell transplantation. Clin Immunol 1999;91:106-16.

9. Wechalekar A, Cranfield T, Sinclair D, Ganzckowski M. Occurrence of autoantibodies in chronic graft vs. host disease after allogeneic stem cell transplantation. Clin Lab Haematol 2005;27: 247-9.

10. Muratori P, Muratori L, Gershwin ME, et al. 'True' antimitochondrial antibody-negative primary biliary cirrhosis, low sensitivity of the routine assays, or both? Clin Exp Immunol 2004;135:154-8.

11. Dähnrich C, Pares A, Caballeria L, et al. New ELISA for detecting primary biliary cirrhosis-specific antimitochondrial antibodies. Clin Chem 2009;55:978-85.

12. Kumagi T, Heathcote EJ. Primary biliary cirrhosis. Orphanet J Rare Dis 2008;3:1. 